\title{
A LUTA DAS MULHERES PELO ESPAÇO PÚBLICO NA PRIMEIRA ONDA DO FEMINISMO: DE SUFFRAGETTES ÀS SUFRAGISTAS
}

\section{THE WOMEN' STUGGLE FOR PUBLIC SPACE IN FIRST WAVE OF FEMINISM: SUFRAGGETTE}

Recebido: 21.06.2017

Aprovado: 10.11.2017

Kimberly Farias Monteiro*

Leilane Serratine Grubba**

RESUMO: A luta das mulheres pela conquista de direitos, especialmente pelo direito civil e político ao voto, foi visível e teve nítido enfoque durante a denominada primeira onda do movimento feminista, que transcorreu pelos séculos XIX e XX. Muitos movimentos marcaram a reivindicação das mulheres pelo direito ao voto, em especial e como um dos mais marcantes, o movimento Sufragista. As Sufragistas, primeiras ativistas do feminismo no século XIX, passaram a ser conhecidas pela sociedade da época devido as suas fortes manifestações públicas em prol dos direitos políticos, com ênfase no direito ao voto. Esse cenário é retratado pelo filme As Sufragistas, estreado no ano de 2015, que relata a luta de mulheres pelo direito ao voto e o movimento sufragista liderado por Emmeline Pankhurst. O artigo problematiza o início da luta de gênero por direitos políticos, com ênfase nos estudos de Direito e Cinema. Dessa forma, a análise do resultado político na luta por direitos da primeira onda do movimento feminista pode ser exemplificado pelo filme As Sufragistas. O filme retrata as condições precárias da mulher no trabalho e sua submissão aos homens; mostra como o Direito e o Cinema podem relacionar-se com o intuito de explorar as realidades vivenciadas pelas mulheres em busca de seus direitos. Nesse sentido, o artigo objetiva, através da análise de cenas e linguagem do filme As Sufragistas, explorar a batalha das Sufragistas pela conquista do voto feminino e, consequentemente, demonstrar que, por meio do Cinema e através de suas imagens é possível retratar as realidades e, assim, as condições às quais as mulheres foram submetidas por longos anos.

Palavras-chave: Direitos Humanos. Direitos Políticos. Cinema. Feminismo.

\footnotetext{
* Mestranda em Direito pela Faculdade Meridional - IMED. Integrantedo Grupode Pesquisa e Extensão Cinema, Direitos Humanos e Sociedade: vias para o empoderamento (IMED/CNPq/YFHRB/IIDH). E-mail: < kimberlyfmonteiro@ hotmail.com >.

** Doutora e Mestre em Direito pela Universidade Federal de Santa Catarina (UFSC).Programa de Pós-Graduação Stricto Sensu em Direito do Complexo de Ensino Superior Meridional (IMED). Professora da Escola de Direito do Complexo de Ensino Superior Meridional (IMED). Pesquisadora da Fundação Meridional. Líder do Centro de Direito, Democracia, Desenvolvimento e Sustentabilidade, da Faculdade Meridional. Pesquisadora do Núcleo de Estudos Conhecer Direito (NECODI). Pesquisadora Coordenadora do Projeto de Pesquisa FUNDDIH - Fundamentos e Dimensões dos Direitos Humanos (IMED/CNPq), além do Projeto de Pesquisa MAR - Migração, Apatridia e Refúgio (IMED/CNPq). Pesquisadora Coordenadora do Projeto de Pesquisa e Extensão CineLaw (Cinema, Direitos Humanos e Sociedade: vias para o empoderamento) (CNPq/IMED/Instituto Interamericano de Derechos Humanos IIDH/ Youth for Human Rights YHRB). Membro do Corpo Diplomático e Consultora de Projetos do Programa das Nações Unidas Youth for Human Rights (YHRB). Publicou os livros O Essencialismo nos Direitos Humanos, Conhecer Direito I e Conhecer Direito II. E-mail: < isgrubba@hotmail.com >.
} 
ABSTRACT: Women's struggle for rights, especially civil and political right to vote, had a clear focus during the first wave of the feminist movement that went through the nineteenth and twentieth centuries. Many movements marked the women's claim to the right to vote, in particular and one of the most striking, the Sufragist movement. Sufragists, the first activists of feminism in the nineteenth century, came to be known by the society of the time due to its strong public manifestations for political rights, especially the right to vote. This scenario is portrayed by the film Suffragette, released in the year 2015, which relates the struggle of women for the right to vote and the suffragist movement led by Emmeline Pankhurst. The purpose of this article is to analyze the beginning of the gender struggle for political rights, with emphasis on Law and Cinema studies. In this way, the analysis of the political outcome in the struggle for rights of the first wave of the feminist movement can be exemplified by the film Suffragette. The film portrays the precarious conditions of women at work and their submission to men; Shows how law and cinema relate to the purpose of exploring the realities experienced by women in search of their rights. In this sense, the present article aims, trought the analysis of scenes and language of the film Suffragette, to explore the battle of Sufragists by the conquest of the feminine vote and, consequently, demonstrate trought the Cinema and trought images it is possible to portray the realities and thus the conditions to which women were submitted.

Keywords: Cinema. Feminism. Human Rights. Political Rights.

\section{INTRODUÇÃO}

O papel fundamental da mulher e a sua importância nas conquistas políticas, econômicas, culturais e sociais foi e ainda é ignorado por muitos na atualidade. Desse modo, a luta das mulheres pelo reconhecimento de seus direitos, tanto no Brasil, quanto no mundo, perdura-se ao longo da história. No Brasil, inicialmente no ano do descobrimento, as condições das mulheres na sociedade chegavam à quase nulidade, pois a sociedade era governada por um sistema patriarcal, reportando a submissão das mulheres pelos homens.

Durante o Brasil Colônia a mulher era vista como alguém incapaz, devendo os seus atos serem tutelados pelos seus pais ou - familiares, e no caso do casamento, pelos seus cônjuges. Essas condições perduraram-se pelo Brasil Império e, até mesmo, pela chegada do Brasil Republicano, o qual foi marcado pela Revolução Industrial, que permitiu o ingresso da mulher no mercado de trabalho, ainda que em condições precárias e sempre inferiorizadas em relação ao trabalho dos homens. Mesmo após muitos anos de incansáveis manifestações, o Código Civil Brasileiro de 1916 ainda referia-se à mulher, enquanto casadas, como alguém incapaz a determinados atos da vida cível, tal como o direito ao voto. 
As mulheres, que foram - e continuam sendo nos dias atuais - marcadas por desigualdade e inferiorização em relação ao sexo e/ou gênero ${ }^{1}$ masculino, uniram-se em meados do século XIX, através de manifestações populares com o intuito de obter o direito civil e político ao voto.

Assim, o feminismo em seu início, enquanto movimento, envolve diversas manifestações responsáveis pela luta das mulheres por igualdade entre homens e mulheres, bem como pela concessão direitos, principalmente pelo acesso aos espaços de decisões políticas. Surgiu a partir das ideias iluministas, entre os anos de 1680 e 1780. Quanto às origens políticas do movimento, essas se tornaram visíveis a partir da Revolução Francesa, em 1789.

Foi logo após a Revolução Francesa, no ano de 1791, que Marie Gouze, mais conhecida como Olympe de Gouges, escreveu Déclaration des droits de la femme et de la citoyenne (Declaração dos direitos da mulher e da cidadã), como uma dedicatória à Rainha Maria Antonieta, mulher de Luís XVI. O documento foi enviado à Assembleia Nacional da França, para que fosse aprovado, da mesma forma que foi a Declaração dos Direitos do Homem e do Cidadão em 1789, documento este que continha apenas os direitos dos homens e cidadãos franceses, entendidos como pessoas do sexo masculino, proprietários e alfabetizados.

O documento escrito por Olympe de Gouges criticou a Declaração dos Direitos do Homem e do Cidadão e também demonstrou o apelo às mulheres para que as mesmas se posicionassem frente aquilo que lhes estava acontecendo. A Declaração dos Direitos da Mulher e da Cidadã contou com 17 artigos que reivindicavam e demonstravam os direitos das mulheres, tais como a igualdade, a liberdade, a justiça, a livre comunicação dos pensamentos e das opiniões, entre outros. Mesmo com algumas mudanças de paradigmas atribuídos às mulheres, alguns artigos elencados na Declaração ainda não se encontram assegurados de maneira sólidas, especialmente, no que se refere a igualdade entre homens e mulheres e o direito à livre comunicação de pensamentos e opiniões.

A igualdade entre homens e mulheres, mesmo reconhecida por diversas declarações e documentos internacionais e locais, ainda não é absoluta nos dias atuais. Do mesmo modo, a livre comunicação de pensamentos, mesmo com um grande número de manifestações realizadas pelas mulheres, por vezes acaba por ser oprimida e, foi devido a esse fato que Olympe de Gouges foi guilhotinada em Paris no ano de 1793, pouco tempo após a sua reivindicação jurídica por iguais direitos entre homens e mulheres.

Desse modo, embora o documento não reivindicasse explicitamente o direito ao voto, essa declaração foi de notável importância na reivindicação por todos os direitos que devem ser concedidos às mulheres, em igualdade aos homens e, assim, juntamente com o movimento feminista merecem atenção e exploração do tema.

Após o histórico movimento de Marie Gouze, pode-se afirmar, genericamente, que o movimento feminista foi dividido teoricamente em três ondas. A primeira onda

1 Neste trabalho acadêmico não se irá dispor acerca das teorias sociais, antropológicas ou jurídicas sobre as diferenças entre sexo e gênero, valendo-se apenas da distinção entre 'homens' e 'mulheres'. Justifica-se, primeiramente, em razão da amplitude do tema; e, secundariamente, em razão do recorte escolhido - o movimento sufragista -, ocorrido em uma época na qual não se abordavam ainda as distinções teóricas entre sexo e gênero. 
ocorreu entre o final do século XIX e o começo do século XX; a segunda onda, entre os anos de 1960 e 1980; e a terceira onda, entre os anos de 1990 a 2000. A primeira onda, que perdurou em todo o mundo, especialmente em países como Reino Unido, Estados Unidos e França, destacou a luta pelo direito civil e político ao voto.

Este artigo tem por objetivo analisar o movimento feminista da primeira onda, com ênfase na luta pelo direito civil e político ao voto, desencadeado principalmente pelo movimento conhecido como Sufragistas. Para tanto, opta-se por analisar o movimento e retratá-lo a partir da sua representação cinematográfica, realizando-se, neste artigo, um estudo de Direito e Cinema - denominado nos Estudos Culturais como film studies (e/ ou movie studies).

Nesse sentido, a questão da luta pelo direito ao voto foi retratada de forma gloriosa pelo filme "As Sufragistas", no original Suffragette, que se passou na Inglaterra, pouco antes da Primeira Guerra Mundial, e mostrou a luta das mulheres pelo direito ao voto, que por anos tiveram seus argumentos ignorados, até ganharem apoio e passarem a firmar-se através do movimento Sufragista liderado por Emmeline Pankhurst.

O filme retratou a vida da personagem principal Maud Watts que, até então, seguia os padrões impostos pela sociedade acerca da posição ou papel da mulher, inferiorizada em relação aos homens, com condições precárias de trabalho e sem direito ao sufrágio. Relata a mudança de posição de Maud após observar as condições em que as mulheres a sua volta e ela, inclusive, eram submetidas.

Ademais, o filme mostrou, além da luta das mulheres por direitos, as consequências reais que essas reivindicações implicaram na época, como torturas, abusos, rejeições familiares e privações de liberdade. Mais ainda, serviu para a compreensão da importância do feminismo enquanto movimento por igualdade, que ganhou força através da luta das mulheres e acabou por desdobrar-se em três ondas, sendo que a primeira onda do feminismo, a qual se consolidou em torno da luta pela igualdade entre homens e mulheres e pela conquista do direito ao sufrágio, será explorada nesse trabalho.

A retratação dofilmeacerca do feminismoeda reivindicação pelo direito ao sufrágio demonstrou a relação entre direito e cinema, ao trazer para a ficção cinematográfica os problemas sofridos pelas mulheres e com desdobramentos até os dias atuais. O cinema é compreendido como uma arte e, além disso, como uma forma comunicação - isto é, uma linguagem.

O cinema é meio de representação das realidades apresentadas por uma sociedade ou, até mesmo, por pequenos grupos de indivíduos, agindo através das imagens e da linguagem utilizada. E, através da linguagem cinematográfica, o espectador estabelece relação com a personagem, com a estória a que assiste, com o lugar em que vê e com o outro. Seus sentidos são instigados em função de uma obra que busca expressão artística através de uma sucessão de imagens projetadas em uma tela. Ao mesmo tempo em que acompanha a representação, o imaginário do espectador é acionado em função de uma interpretação subjetiva e social.

Assim, como meio para se mostrar a realidade de um grupo, inserido em um importante período histórico, o filme As Sufragistas demonstra a luta e a reivindicação 
por igualdade entre homens e mulheres, e, consequentemente, na obtenção do direito ao voto para as mulheres. Além disso, importante salientar essa interdisciplinaridade entre o filme apresentado e o Direito, enquanto sistema jurídico que cumpre com sua função de gerar interpretações sociais e pensamento crítico acerca do assunto, possibilitando o desenvolvimento de estudos e debates em relação às realidades vividas na história mundial.

Desse modo, para realização da pesquisa, primeiramente será abordado o contexto histórico do feminismo e a sua primeira onda, concomitantemente e através da análise do filme As Sufragistas. Posteriormente, será abordado o desenvolvimento humano feminino e como se da a posição das mulheres no parlamento, tanto no Brasil, quanto em alguns casos representativos no mundo, até os dias atuais. Quer dizer, mesmo diante da luta das mulheres pelo direito ao voto e a elegibilidade, alcançaram as mulheres a vontade e o acesso aos parlamentos, sendo eleitas para cargos de representatividade política?

\section{O CONTEXTO HISTÓRIO: AS SUFRAGISTAS E A PRIMEIRA ONDA DO FEMINISMO}

Desde a antiguidade, as mulheres de todo o mundo encontravam-se em relações inferiores aos homens no que se refere às diversas situações do dia-a-dia e não possuíam direitos próprios que hoje são considerados basilares, como direito ao estudo e direito ao voto. Possuíam os papeis que se relacionavam prioritária e exclusivamente ao âmbito doméstico, como a atribuição de ser esposa, filha, mãe, bem como de cuidar da casa. No Brasil, a exemplo, entre os anos de 1500 a 1822, momento que foi chamado de Brasil Colônia, o país era dominado por um sistema patriarcal e as mulheres não eram detentoras de direitos próprios. À época, seus únicos afazeres destinavam-se às atividades domésticas, sendo que a elas eram atribuídos apenas dois papéis, o de mãe e o de esposa. Em contrapartida, aos homens eram concedidos direitos como o direito ao estudo e o poder na tomada de decisões (FERNANDES, 2015).

Ademais, tal qual como constava nas Ordenações Filipinas, publicada pelo então Rei de Portugal, Felipe II, "a mulher necessitava de permanente tutela, porque tinha fraqueza de entendimento." (PENA, 2008).

$\mathrm{O}$ direito à educação foi concedido às mulheres em 1827, na época do Brasil Império, mas o aspecto principal continuava sendo a preparação para as atividades domésticas. Ainda, era admitido que as mesmas estudassem até o primeiro grau, sendo assim, impossível de se atingir níveis mais altos ou superiores no estudo, o que era concedido aos homens (TELES, 1993).

Situações como essa não ocorreram apenas na história brasileira. Nesse sentido, por exemplo, nos anos 1920, a escritora Virginia Woolf (1990) criticou o depredador cultural do ocidente - patriarcalismo - sob o argumento de que os valores universais construídos haviam deixado as mulheres relegadas ao âmbito doméstico. Essa dicotomia entre o âmbito público e privado possibilita justificar a mencionada condenação à morte de Marie Gouze (Olympe de Gouges), que reivindicou, já na época da formulação de 
Direitos do Homem e do cidadão, a condição de sujeito para a atuação na esfera pública, por meio de sua anti-declaração patriarcal, a Declaração dos Direitos das Mulheres e Cidadãs.

A fundamentação história da separação entre os espaços público (homem) e privado (mulher), fez com que os trabalhos de cuidado tenham sido atribuídos historicamente às mulheres, bom como se realizam no e desde o âmbito privado e doméstico; não tendo sido considerados trabalhos para os fins de garantia da titularidade de direitos (MESTRE, 2005).

De fato, desde a tradição grega da Deusa Irene, aos homens se atribuiu a função da guerra (espaço público) e às mulheres a função da paz (espaço privado).Diante disso, ao longo da história muitas mulheres desafiavam as funções a elas atribuídas, como a mencionada função de esposa e dona de casa, assim como às limitações das mulheres às questões domésticas e à exclusão a que eram submetidas no que se refere ao espaço público, inclusive às exclusões sobre os assuntos da sociedade, dentre eles, o direito de votar. Por anos, as mulheres lutaram e continuam lutando para adquirir as suas liberdades e seu espaço de direito, na sociedade. Desse modo, originou-se o feminismo, o qual é responsável por manifestações, movimentos e ideologia das mulheres na luta pelo reconhecimento de igualdade social, cultural, política, sexual e econômica (KLEBIS, 2015).

O feminismo, de modo geral, buscou, desde o início, a análise do fenômeno do patriarcalismo, denunciando as opressões, as construções históricas, as possibilidades de libertação, percebendo-o principalmente como um sistema de relações dominantes que impõe um padrão de valores e de comportamentos à sociedade. Em suma, para Young, o feminismo não se configura em uma doutrina ou teoria, mas em um compromisso teórico com a questão da mulher, concretamente situada no mundo material, nos contextos de dominação e de libertação (MARION YOUNG, 1997).

O movimento feminista teve como influência Simone de Beauvoir, filósofa e escritora francesa, nascida em Paris no dia 9 de janeiro de 1908. Criada em uma família tradicional católica, sua mãe garantiu que a mesma teria uma educação conservadora no Cours Desir, também chamado de Escola do Abbey, onde meninas recebiam formação para que fossem donas de casa e mães de família. Diferente da grande maioria das meninas e mulheres da sua classe social à época, Simone não se conformou com o destino que já lhe estava traçado, qual seja, o de um casamento arranjado.

Conforme Ribeiro (2014), Simone foi vista como ameaça no século XX, por fazer parte de uma revolução feminista, na qual as mulheres pudessem ter voz na sociedade. Era uma mulher singular, a qual pensava diferente da norma masculina hegemônica patriarcalista e não acreditava ou concordava que a mulher fosse limitada a condição natural que lhe era imposta, desde o nascimento, que era restrita a um comportamento padrão, no qual as mulheres deveriam casar-se, através de um casamento arranjado, ter filhos e serem donas de casa. Conforme a mesma escreveu: "Nenhum destino biológico, psíquico ou econômico define a forma que a fêmea humana assume no seio da sociedade; é o conjunto da civilização que elabora esse produto intermediário entre o macho e o 
castrado que qualificam de feminino". (BEAUVOIR, 1980).

Em 1926, a pensadora iniciou o curso de filosofia na Universidade de Paris, sendo que cinco anos depois passou a lecionar filosofia, escrevendo romances em seu tempo livro. Foi em 1949 que Simone publicou o livro "O Segundo Sexo", o qual colocou as mulheres no centro do debate e detalhou as suas condições de opressão e inferiorização em relação aos homens na sociedade.

Para a sociedade conservadora da época, o livro representou um escândalo moral, pois atrás dele estava o papel de uma mulher que não aceitava a condição que lhe era imposta, opondo-se através de seus escritos. O livro representou, mais do que nunca, um questionamento ao conceito de gênero enraizado na base material e cultural das sociedades ocidentais, que faz com que uma simples diferença biológica entre homens e mulheres seja utilizada para moldar uma construção imaginária das noções de masculinidade e de feminilidade, e faz com que as diferenças constituam desigualdades. A Igreja Católica rejeitou o livro, determinando-o como obra proibida.

Desse modo, o livro de Simone de Beauvoir foi e continua sendo, até os dias atuais, de grande importância, pois se propôs a discutir as diferenças entre homens e mulheres instituídas na sociedade da época, estabelecendo uma reflexão filosófica e sociológica do papel da mulher e, principalmente, contribuindo para que se projetassem os caminhos do feminismo a partir de então.

Assim como o livro O Segundo Sexo, o filme As Sufragistas, também retratou um movimento feminista anterior aos escritos de Simone de Beauvoir, que apesar de não ter questionado o conceito de gênero, lutou para que as mulheres ocupassem os espaços públicos. Nesse sentido, o filme retratou as condições das mulheres à época e a inferiorização do sexo feminino em relação ao masculino, adentrando na questão da luta por direitos, principalmente, o direito ao sufrágio.

O filme As Sufragistas ${ }^{2}$, produzido em 2015, refere-se ao histórico acontecimento do movimento sufragista inglês que ocorreu pouco antes da Primeira Guerra Mundial. O filme retratou, a partir de cenas dramáticas e impactantes, a luta das mulheres pelo direito ao voto, que por anos tiveram seus argumentos ignorados, até ganharam apoio e passaram a firmar-se através do movimento Sufragista liderado por Emmeline Pankhurst. Assim, o filme mostrou a vida da protagonista Maud Watts que como muitas mulheres da classe trabalhadora nos anos de 1912, seguia os padrões da sociedade. Tudo estava normal em seu cotidiano, trabalhando, sendo mãe e esposa até que Maud, após presenciar os tumultos e confusões causados por algumas mulheres que atiravam pedras em vitrines, enquanto clamavam pelo direito ao voto feminino, começou a questionar-se se realmente a sua vida, o "seu normal" as condições a que era submetida, eram realmente natural.

No decorrer do filme, pode-se ver as péssimas condições das trabalhadoras do sexo feminino, que sofriam com a precária infraestrutura e adoeciam por conta dos gases emitidos pelas máquinas, além dos abusos sexuais sofridos por parte de seus

2 O filme dirigido por Sarah Gavron e roteiro de Abi Morgan é estrelado por Carey Mulligan e traz ainda em seu elenco principal Helena Bonham Carter, Brendan Gleeson, Anne-Marie Duff e Meryl Streep - com participação curta mas de grande impacto e importância ao roteiro. 
empregadores, ganhando um salário ínfimo e sempre inferior ao dos homens que nessa fase poderiam ser vistos nos Parlamentos, decidindo as questões da sociedade.

Inicialmente Maud não se identificava como uma Sufragista, pois julgava ser natural as suas péssimas condições de trabalho, os abusos sofridos por parte do marido, a negação de sua liberdade e a inferiorização das mulheres pelos homens. Porém, após Maud observar toda a situação das mulheres a sua volta, lutando pelo direito ao voto, a mesma percebeu que não poderia fechar os olhos para algo tão importante, que arrastava dezenas de mulheres para as ruas e as faziam lutar incansavelmente, apesar dos ataques constantes sofridos. Assim, Maud passou a lutar juntamente as demais pelos seus direitos e tornou-se uma militante do movimento Sufragista, chegando a ser encarcerada.

A luta das mulheres pelo direito ao voto implicou em torturas, rejeições familiares e levou muitas mulheres a serem crucificadas pela sociedade e, por diversas vezes, terem suas liberdades restringidas.

Assim, buscando ter o direito ao voto reconhecido, o feminismo desdobrou-se em três momentos sendo estes, a Primeira Onda, que ocorreu entre o final do século XIX e o começo do século XX; a Segunda Onda, entre os anos de 1960 e 1980; e a Terceira Onda, entre os anos de 1990 a 2000 (KLEBIS, 2015).

A primeira onda do feminismo aconteceu a partir das últimas décadas do século XIX. As mulheres, primeiramente na Inglaterra, organizaram-se para reivindicar seus direitos, dentre eles o direito ao voto. Como narrado no filme supracitado, as Sufragetes, como ficaram conhecidas eque, inicialmente era um termo utilizado pelo jornal The Daily Mail para ridicularizar o movimento (KLEBIS, 2015), foram responsáveis por diversas manifestações em Londres, as quais geraram inúmeras polêmicas e revoltas a boa parte da sociedade da época e, ao mesmo tempo, comoção por parte de mulheres militantes da causa. As militantes do movimento foram presas várias vezes e fizeram greves de fome. Em 1913, na famosa corrida de cavalo em Derby, a feminista Emily Davison, jogou-se a frente do cavalo do Rei da Inglaterra, vindo a falecer (PINTO, 2010). O trágico incidente ocorrido no Hipódromo de Epsom Downs levou milhares de mulheres às ruas, durante o funeral de Emily, clamando pelo direito ao voto, marcando uma manifestação de visível importância para o movimento Sufragista.

O primeiro momento do feminismo da primeira onda foi caracterizado pelo seu cunho conservador, questionando a divisão sexual dos papeis exercidos entre homens e mulheres. As mulheres contestavam as diferenças contratuais e econômicas, diferença na capacidade por escolher aquilo que lhe era conveniente, ou seja, diferença na liberdade que lhes era concedida e, sobretudo, a diferença política, pois eram proibidas de votar e escolher por quem gostariam de ser representadas.

A bióloga Bertha Maria Júlia Lutz, nascida em São Paulo, no ano de 1894, foi a precursora da primeira onda do feminismo no Brasil e responsável por movimentos e ações políticas que culminaram na criação de leis que concederam o direito ao voto às mulheres brasileiras, ficando conhecida mundialmente como a maior líder na luta pelos direitos políticos das mulheres brasileiras (BRASIL, 2014). 
Foi educada na Europa e no ano de 1918 voltou ao Brasil, formada em ciências naturais pela Universidade de Paris - Sorbonne. E, foi durante a sua estadia na Europa em que tomou conhecimento dos movimentos feministas da época, entrando em contado com a campanha sufragista. Em 1919, tornou-se a segunda mulher a ingressar no serviço público brasileiro, após ser aprovada em concurso para bióloga do Museu Nacional, passando a ser destaque na busca pela igualdade de direitos jurídicos entre homens e mulheres.

Criou, também em 1919, juntamente com outras mulheres, a Liga para a Emancipação Intelectual da Mulher. Ainda, ano de 1922, representou o Brasil na Assembleia geral da Liga das Mulheres Eleitoras, nos Estados Unidos, onde foi eleita vice-presidente da Sociedade Pan-Americana e, ao regressar, criou a Federação Brasileira pelo Progresso Feminino, que substituiu àquela criada em 1919, iniciando assim, a luta pela obtenção do direito ao voto pelas mulheres.

Após a revolução de 1930, o movimento sufragista alcançou aquilo que há tantos anos buscava: o direito ao voto. Foi em 1932, pelo Decreto-lei ${ }^{0} 21.076$, de 24 de fevereiro de 1932, do Presidente Getúlio Vargas. Em seu artigo segundo estabelece-se que: " É eleitor o cidadão maior de 21 anos, sem distinção de sexo, alistado na forma deste Código" (BRASIL, 1932 ).

Bertha participou do comitê elaborador da Constituição em 1934 e garantiu às mulheres a igualdade de direitos políticos. Assim, iniciou-se a sua carreira política de fato. Elegeu-se primeira suplente de deputado federal pela Liga Eleitoral Independente, sendo que em 1936 assumiu a cadeira na Câmara Federal, após a morte do deputado Cândido Pereira. À frente do cargo defendeu mudanças na legislação referentes ao trabalho da mulher e do menor, a isenção do serviço militar, a licença de três meses para a gestante e a redução da jornada de trabalho, então de 13 horas.

Com a repercussão das lutas do movimento feminista, em âmbito internacional, a Assembleia Geral da Organização das Nações Unidas, declarou o ano de 1975 como o Ano Internacional das Mulheres e organizou a primeira Conferência Mundial sobre as Mulheres, na Cidade do México. Bertha, atendendo a um convite da Presidência da República e do Ministério das Relações Exteriores, integrou a delegação brasileira no evento. Seguindo o estímulo da Conferência, os anos de 1976 a 1985, foram declarados a Década da Mulher. Como se pôde ver, a influência de Bertha Lutz na luta pela aquisição do direito ao voto das mulheres brasileiras foi fundamental para tal conquista. Desse modo, a bióloga que anos mais tarde graduou-se em direito, representou de forma memorável as mulheres ao defender direitos e princípios considerados fundamentais, mostrando que lugar de mulher é também no centro das decisões do país, sejam elas econômicas, sociais e, sobretudo, políticas.

\section{DESENVOLVIMENTO HUMANO FEMININO}

A luta das mulheres em busca de emancipação e do empoderamento contou com o suporte do movimento feminista. De forma organizada e através de muitas batalhas travadas contra uma sociedade historicamente patriarcal, as mulheres conquistaram direitos essenciais como direito à educação, ao trabalho e o direito político de votar e ser votada para cargos de representatividade. 
A liderança das mulheres na sociedadee o seu desenvolvimento merecem destaque e estudo, mesmo que de forma breve, acerca de sua evolução frente à reivindicação de direitos, sobretudo de direitos políticos. Para demonstrar a relação da liderança das mulheres e o desenvolvimento, pode-se destacar um trecho citado por Amartya Sen (2000), que destaca a condição de agente das mulheres como aspecto do desenvolvimento humano sustentável:

\footnotetext{
O grande alcance da condição de agente das mulheres é uma das áreas mais negligenciadas nos estudos sobre o desenvolvimento e requer correção urgente. Pode-se dizer que nada atualmente é tão importante na economia política do desenvolvimento quanto um reconhecimento adequado da participação e da liderança política, econômica e social das mulheres. Esse é, de fato, um aspecto crucial do desenvolvimento com liberdade.
}

Os espaços de poder dos sistemas políticos democráticos, representados nesse contexto pelos poderes Legislativo, Executivo e Judiciário, é uma das dimensões sociais em que a baixa inserção das mulheres ganha destaque. Historicamente, os homens vêm dominando a política e as mulheres têm dificuldades de se ver participando deste espaço. Isso ocorre, pois permanecem em grande medida vigentes os papéis de gênero tradicionais e a divisão sexual do trabalho.

Porém, embora ainda haja predominância dos cargos políticos ocupados pelo sexo masculino, as mulheres passaram a ocupar o seu espaço na política mundial, após lutas e reivindicações pelo direito ao sufrágio, sendo que muitas dessas conquistas foram alcançadas pelos movimentos feministas instituídos pelo mundo. Nesse sentido, “A democracia deve proporcionar condições para que as mulheres manifestem suas perspectivas, ideias, demandas e necessidades nos espaços em que são tomadas as decisões que dizem respeito a toda a sociedade." (BRASIL, 2016).

Importante ressaltar que, apesar da luta pelo sufrágio e elegibilidade das mulheres, ainda há muito a ser feito em nível mundial, conforme aponta o Índice de Desigualdade de Gênero ${ }^{3}$ (IDG) das Nações Unidas (2010, p. 92-98), que inclui três dimensões - saúde reprodutiva, capacitação e participação no mercado de trabalho -, para analisar a desigualdade por comparação entre dois grupos - mulheres e homens - captando a perda de progressos nas dimensões supramencionadas, por meio de uma variação entre 0 (nenhuma desigualdade nas dimensões) e 1 (desigualdade total), aumentando quando são associadas desvantagens em todas as dimensões (desvantagens sobrepostas). Conforme o IDG, houve um aumento da representação parlamentar das mulheres (liderança política), embora a média global seja de apenas 16\%. Além disso, a participação política das mulheres na África Subsaariana é maior do que nos Estados Árabes. Assim, apesar do aumento do índice de mulheres elegidas para liderança política, percebe-se que a sua participação política em $16 \%$ do total ainda é aquém da participação masculina.

Ainda, dados do Relatório de Desenvolvimento das Nações Unidas de 2011 apontam para o fato da sub-representação das mulheres nos parlamentos nacionais. Elas ocupam

3 Segundo o Relatório de desenvolvimento humano de 2011, das Nações Unidas (2011, p. 30), os lugares com os níveis mais elevados de desigualdade de gênero no mundo, medidos pelo IDG, conduziram a níveis mais baixos de sustentabilidade ambiental e da vida humana. 
aproximadamente apenas $19 \%$ dos assentos parlamentais, assim como apenas $18 \%$ dos assentos ministeriais. De fato, existem apenas 7 chefes de Estado mulheres eleitas, ao passo que existem 150 homens. Além disso, apenas 11 dos 192 chefes de governo são mulheres (NAÇÕES UNIDAS, 2011, p. 66-67).Garantir a participação plena e efetiva das mulheres e a igualdade de oportunidade para liderança na tomada das decisões em todos os âmbitos, sejam esses sociais, econômicos ou políticos, e adotar e fortalecer políticas sólidas e legislação aplicável para a promoção de igualdade de gênero e empoderar todas as mulheres e meninas em todos os níveis são algumas das 17 metas globais do Objetivos de Desenvolvimento Sustentável (ODS) quanto à Igualdade de Gênero.

O Brasil ocupa a $158^{\circ}$ posição, de um total de 188 países, em relação à presença feminina de mulheres no parlamento. Se essa comparação for feita igualmente entre países da América do Sul, o Brasil ocupa a última posição. (NAÇÔES UNIDAS, 2016)

A Lei 9.504, de 30 setembro de 1997, ao estabelecer normas para a eleição, dispôs que cada partido ou coligação devera reservar o mínimo de $30 \%$ e o máximo de $70 \%$ para candidaturas de cada sexo. A lei anterior, Lei 9.100, de 2 de outubro de 1995, previa uma cota mínima de $20 \%$ para a candidatura das mulheres (BRASIL, 2016). No Brasil, a adoção dessas medidas visa alcançar o dever da promoção de igualdade entre homens e mulheres, por meio de ações afirmativas. Contudo, o número de mulheres nos parlamentos ainda é ínfimo.

É importante salientar que as mulheres constituem mais da metade da população brasileira, sendo que, sua presença no parlamento não chega a 10\%. Do ponto de vista eleitoral, as mulheres detêm menos recursos do que os homens, tanto financeiro quanto em relação ao tempo, e ainda, há o fato dos homens apresentarem-se em um número muito superior em relação às mesmas, e esse acesso restrito das mulheres na política, dificulta as suas candidaturas.

Ainda, conforme a Secretaria de Políticas para as Mulheres (2016), devido à falta de recursos, a grande maioria das mulheres quando candidatam-se, tendem a se candidatar mais por circunscrições territoriais menos vistas do que nas circunscrições maiores e nas regiões mais desenvolvidas, pois os custos de uma eleição são mais baixos em circunscrições menores e há a presença de menos partidos disputando as eleições. Os resultados das eleições municipais dos anos de 2004, 2008 e 2012 confirmam tal analise, pois verifica-se que o número de candidatas às prefeituras e às Câmaras Municipais quanto o número de eleitas aumentou. O percentual de crescimento foi de $25,4 \%$, sendo que a média de eleitas foi 12,8\%, demonstrando que mesmo a nível local há certa dificuldade nas eleições.

Pode-se notar que o crescimento do número de mulheres no parlamento acontece, mas se ocorre de forma lenta. Nos anos anteriores, de 1995 a 1998, o percentual de mulheres eleitas para o cargo de vereadoras era de $7 \%$ de um número de 52.962 vereadores eleitos, sendo que em 2000 o percentual elevou-se a $11 \%$ dos 58.323 vereadores eleitos. Já em 2008, 6.501 mulheres foram eleitas, representando 12,5\% dos 51.908 vereadores eleitos. (BRASIL, 2016).

Ainda, segundo a ONU MULHERES dispõe no seu documento "O Progresso das Mulheres no Brasil 2003-2010"' (2011), na esfera do Poder Legislativo Federal, a 
representação das mulheres na Câmara dos Deputados, nos anos de 1995 e 1998, era de apenas $6 \%$ dentre um número de 513 deputados, sendo que, em 2002 houve um aumento para $8,19 \%$. No Senado Federal a representatividade das mulheres é ainda mais reduzida 2,46\% em 1995 e 6,17\% em 2000, do total de 81 senadores. Em 2010, das 930 candidatas à Câmara dos Deputados, apenas 45 mulheres foram eleitas em um número total de 513 deputados/as, correspondendo a $8,77 \%$, ao passo que os homens ocupam as outras 468 cadeiras, ou seja, 91,23\%. Dos 54 senadores eleitos em 2010, apenas 8 foram mulheres, o que representa $14,8 \%$.

Já em 2014 as eleições para a Câmara dos Deputados e Senado Federal apresentaram resultados poucos favoráveis à representação política das mulheres nesses espaços. As bancadas femininas das duas casas aumentaram, mas as mulheres ainda permanecem na sub-representação dessa parcela da população brasileira.

Em relação ao Poder Executivo, é impossível não mencionar a eleição da Presidenta Dilma Rousseff, no ano de 2011, sendo a primeira Presidenta eleita na história do Brasil, somando-se ao universo de 11 mulheres chefes de Governo, em um número de 192 países. Nas palavras da Presidenta:

Pela decisão soberana do povo, hoje será a primeira vez que a faixa presidencial cingirá no ombro de uma mulher. (...) sei que o meu mandato deve incluir a tradução mais generosa desta ousadia do voto popular que, após levar à Presidência um homem do povo, decide convocar uma mulher para decidir os destinos do país. (...) Para além da minha pessoa, a valorização da mulher melhora a nossa sociedade e valoriza nossa democracia. (BRASIL, 2016).

Na esfera Estadual, no ano de 2000, apenas duas mulheres foram eleitas a Chefia do Governo. No Poder Executivo Estadual, nos anos de 1994, 1998 e 2000 a representatividade de mulheres eleitas para o cargo do Governo do Estado continuou em $4 \%$, contando apenas com uma governadora em um número de 27 governadores. Em 2002, a representatividade aumentou para 8\%, com a eleição de duas governadoras. Em 2010 o número ficou em 10,7\% e em 2014 passou para 12,12\%. (BRASIL, 2011)

.No âmbito Federal, em 2003, cinco ministras tomaram posse encarregadas dos Ministérios do Meio Ambiente, Assistência e Promoção Social, Minas e Energia e das Secretarias Especiais de Políticas para as Mulheres e de Políticas de Promoção da Igualdade Racial. Para o Brasil até 2011, esse havia sido o maior número de mulheres na chefia do Governo Federal, sendo pertinente destacar que três Ministras eram afrodescendentes. Em 2011 a presidente Dilma Rousseff determinou que um terço de seu Ministério fosse integrado por mulheres, objetivando impulsionar, o empoderamento das mulheres. (BRASIL, 2011). Nesse caso, assenta-se a maior importância à Ministras mulheres e afrodescendentes, considerando-se o local desprivilegiado das mulheres com relação aos homens, mas ainda privilegiados das mulheres brancas para com relação às mulheres afrodescendentes, indígenas e de grupos tidos como vulneráveis e/ ou minoritários.

Já no Poder Judiciário, referindo-se ao Supremo Tribunal Federal, até o ano 200o, nenhuma mulher havia sido Ministra. Ainda, até esse ano nenhuma mulher poderia 
frequentar as dependências da Suprema Corte usando calças compridas, pois a tradição requeria o uso de saias ou vestidos. Porém no dia 3 de maio de 2000 essa regra foi derrubada, durante uma sessão administrativa os Ministros passaram a permitir o uso de calças compridas pelas mulheres, desde que acompanhadas de blazer. Essa mudança já avistava uma nova era da Suprema Corte, pois no ano de 2001 a Ministra Ellen Grace Northfleet tomou posse no Supremo, exercendo a presidência da corte nos anos de 2006 a 2008. (BRASIL, 2011)

A representatividade das mulheres nos Tribunais Superiores ainda é muito inferior ao que se espera. Até 1995 nenhuma ocupava cargos em Tribunais. Em 1998 passou para 2\%, em 2001 a $8,20 \%$ e em 2003 a 9,09\%. Na primeira instância jurisdicional a participação das mulheres chega a 30\%. Já no Superior Tribunal de Justiça, a representatividade das mulheres fica em 16,7\% de um total de 33 membros. Ou seja, somente cinco mulheres são Ministras. Em 2010, apenas 15,73\% dos 93 cargos dos Tribunais Superiores (Supremo Tribunal Federal, Superior Tribunal de Justiça, Superior Tribunal Militar, Tribunal Superior do Trabalho e Tribunal Superior Eleitoral) eram integrados por mulheres - totalizando o reduzido universo de 14 mulheres na alta cúpula do Poder Judiciário. (BRASIL, 2011).

Com relação aos demais continentes, segundo dados da União Parlamentar (2016), às Américas, que tem tido a média regional mais alta de mulheres parlamentares, passaram a representar 27,2\%, um aumento de o,8\%. Já em relação à África Subsaariana teve umaumento de $0,7 \%$, com uma média regional de $23,2 \%$. Os maiores ganhos foram na Etiópia e na Tanzânia, devido principalmente às cotas. Do mesmo modo, a média regional na Europa subiu 0,4\% para 25,4\% de mulheres parlamentares. O que teria contribuído para esses aumentos foram as Cotas voluntárias adotadas por partidos políticos no Reino Unido e uma lei sobre igualdade na Espanha. $\mathrm{O}$ mundo árabe continua avançando em relação à participação política feminina, aumentando sua média regional em $0,3 \%$. As regiões da Âsia e do Pacífico, no entanto, permaneceram praticamente estáticas, com um aumento de apenas o,1\% em seus números de mulheres no parlamento, sendo as regiões com progresso mais lento nos últimos dez anos.

Contudo, um aumento do número de mulheres presidentes de parlamentos em 2015 e alguns sucessos regionais ganham pouco destaque devido ao fato de a União Interparlamentar ter considerado esse ano como "mais um ano decepcionante" em relação à participação feminina nos parlamentos. (NAÇÕES UNIDAS, 2016).

Assim, conforme a União Interparlamentar (2016), o número de mulheres no parlamento do mundo subiu apenas o,5 ponto percentual em 2015, representando $22,6 \%$ dos membros dos parlamentos e, ficando abaixo do crescimento dos anos anteriores. A UIP defende que, apesar deste número ser recorde e representar uma continuação da tendência de alta, o índice do progresso em 2015 foi mais um recuo em comparação ao aumento de 1,5\% observado em 2013.

Com esse aumento quase que insignificante, o ano de $2015 \mathrm{fez}$ pouco para passar esperança e confiança de que o aumento do número de mulheres no Parlamento irá ter um grande crescimento ao longo dos anos, conforme o que vem sendo esperando pelas mulheres e pela sociedade em geral. 
O anterior secretário-geral da ONU, Ban Ki-moon, destacou que a "comunidade internacional estabeleceu novas metas sobre igualdade de gênero e a plena e igual participação das mulheres em todos os níveis de tomada de decisão nos próximos 15 anos”. Nesse sentido, a União Interparlamentar destaca a necessidade de enfrentar impedimentos a mulheres para que concorram a cargos, a falta de recursos financeiros adequados para a realização da campanha e o papel que os partidos políticos devem fazer para dar o suporte necessário para o ingresso das mulheres na esfera política. (NAÇÕES UNIDAS, 2016)

Desse modo, embora oaumento das mulheres nos Parlamentos venha acontecendo gradualmente, este ainda está muito aquém do esperado e do que merecido, devido à trajetória da luta das mulheres durante séculos para conseguir alcançar o direito de votar e ser votadas e, sobretudo, devido ao fato de constituírem seus direitos por natureza. Mais do que isso, o local ainda privilegiados das mulheres brancas com relação às mulheres de grupos minoritários no ocidente, como as mulheres afrodescendentes, indígenas, homossexuais, dentre outras.

Se é verdade que a natureza excludente da cidadania somente foi mudada, de um modo geral, com a extensão do sufrágio universal, no século XX (VIEIRA, 200o)*; não se pode esquecer da importância das manifestações das mulheres visando o seu reconhecimento enquanto sujeitos - além de outros grupos tidos como minoritários -, como as protagonistas femininas que lutam pelo processo histórico da paz, permitindo dar uma identidade sexual à história normalmente pensada sob o ponto de vista masculino. Assim, uma revisão do conceito de poder patriarcal (DÍEZ JORGE; MIRÓN PÉREZ, 2009, p. 67-93).

\section{CONSIDERAÇÕES FINAIS}

O presente trabalho foi dedicado ao estudo da luta das mulheres na busca do direito ao voto, bem como, ao movimento feminista, especialmente da sua primeira onda e o desenvolvimento humano feminino nas esferas políticas parlamentares tanto no Brasil, quanto no mundo, após a conquista do direito ao sufrágio.

O artigo desenvolveu-se de modo a demonstrar, através do filme As Sufragistas, o a possibilidade da relação entre Cinema e Direito, mostrando como a arte desempenha um papel de extrema importância ao conseguir retratar as realidades sociais, culturais e políticas da história, tendo a função primordial de fazer uma reflexão e análise crítica acerca da história.

Assim, no primeiro capítulo, buscou-se analisar o contexto histórico à volta da conquista do direito ao voto pelas mulheres, assim como, o movimento feminista em sua primeira onda e, consequentemente, o movimento sufragista, após uma análise do filme As Sufragistas. Desse modo, o filme retratou a luta árdua das mulheres, durante décadas,

4 Apontamos para o fato de que, mesmo assim, os não-alfabetizados continuaram excluídos do sufrágio universal e, portanto, excluídos de parte de suas manifestações cidadãs (cidadania por engajamento). Todavia, no âmbito desse trabalho, não nos deteremos, em virtude do enfoque adotado, a analisar essa questão e os diversos posicionamentos que comporta. 
para conquistar o direito ao voto, bem como, as suas implicações que resultaram em rejeições familiares, torturas, abusos e privação de liberdade. As mulheres passaram a opor-se às condições sociais que lhes eram impostas e começaram a buscar os seus direitos. Pode-se concluir que o movimento feminista, através da sua primeira onda que reivindicava, além da igualdade entre homens e mulheres, o direito ao sufrágio, foi primordial na conquista das mulheres, pois permitiu que as mesmas se reunissem de forma organizada e mais fortalecida na reivindicação pelos seus direitos.

Ainda, na mesma seção, retratou-se a influência na luta do movimento feminista, de Simone de Beauvoir, a qual apesar da inserção em uma sociedade e família tradicionais e conservadoras, não conformou-se com a condição de vida que a mulher deveria ter conforme os padrões da sociedade e que lhe era imposta à época, e resolveu lutar pela garantia dos seus direitos. Do mesmo modo fez Bertha Lutz, brasileira, precursora da primeira onda do feminismo no Brasil, segunda mulher a ingressar no serviço público brasileiro, que passou a ser destaque na busca pela igualdade de direitos jurídicos entre homens e mulheres.

Em um segundo momento, o artigo buscou analisar o desenvolvimento humano feminino nasesferas dos poderesexecutivo, legislativoejudiciárioe ocrescimentodemulheres nos parlamentos mundiais. Dessa forma, constatou-se que, embora haja crescimento de forma gradual, esse ainda considera-se aquém das expectativas de aumento que foram auspiciadas não só pelas mulheres, mas por boa parte da sociedade em geral. Sendo que, deve-se haver suporte e fortalecimento das mulheres para que as mesmas consigam, cada vez mais, alcançarem seus lugares - de direito - nos parlamentos mundiais.

\section{REFÊRENCIAS}

BEAUVOIR, Simone. O Segundo sexo: fatos e mitos. 4 ed. São Paulo: Difusão Européia do Livro, 1980.

BRASIL. Bertha Lutz. Brasília: Cidadania e Justiça. 2014. Disponível em: < http://www. brasil.gov.br/cidadania-e-justica/2012/o4/bertha-lutz >. Acesso em: 10 mai. 2017.

Câmara dos Deputados. Decreto-Lei n.21.o76, de 24 de janeiro de 1932. Disponível em: < http://www2.camara.leg.br/legin/fed/decret/1930-1939/decreto-21076-24-fevereiro1932-507583-publicacaooriginal-1-pe.html >. Acesso em: o8 mai. 2017.

ONU MULHERES. O Progresso das Mulheres no Brasil 2003-2010. Rio de Janeiro: Outubro, 2011. Disponível em: < http://onumulheres.org.br/wp-content/ themes/vibecom_onu/pdfs/progresso.pdf >. Acesso em: o7 mai. 2017.

Plataforma Mais Mulheres no Poder. Brasília: Secretaria de Políticas para as Mulheres, 2016. Disponível em: < http://www.spm.gov.br/central-de-conteudos/ publicacoes/2016/plataforma-mais-mulheres-no-poder-2016_web.pdf >. Acesso em: 07 mai. 2017. 
DÍEZ JORGE, Maria Elena; MIRÓN PÉREZ, Maria Dolores. Una paz feminina. In MOLINA RUEDA, Beatriz; MUÑOZ, Francisco A. (ed.) Manual de Paz y Conflictos. Granada: Universidad de Granada - Instituto de la Paz y los Conflitctos, pp. 67-93. Disponível em: < http://www.ugr.es/ gijapaz/Manual/Una\%2oPaz\%20Femenina.pdf >. Acesso em: 03 jan. 2009.

FERNANDES, Valéria Diez Scarance. Lei Maria da Penha: o processo penal no caminho da efetividade: abordagem jurídica e multidisciplinar (incluí Lei de Feminicídio). s/d. São Paulo: Atlas, 2015.

FRANÇA, Fabiane Freire; RIBEIRO, Tamires Almeida. Simone de Beauvoir e o movimento feminista: contribuições à Educação. Anais do III Simpósio Gênero e Políticas Públicas. Maio, 2014. Disponível em: < http://www.uel.br/eventos/gpp/pages/ arquivos/GT6_Tamires\%2oAlmeida\%2oRibeiro.pdf >. Acesso em: 10 mai. 2017.

GOUGES, Olympe de. Declaração dos direitos da mulher cidadã. Tradução de Selvino José Assmann. Revista Internacional Interdisciplinar Interthesis. Florianópolis. vol. 4. n. 1. Janeiro/Junho, 2007. Disponível em: < https://periodicos.ufsc.br/index.php/ interthesis/article/viewFile/911/10852 >. Acesso em: o8 mai. 2017.

KLEBIS, Daniela. O movimento feminista no Brasil e no mundo. Revista PréUnivesp. n. 61. Setembro, 2015. Disponível em: < http://pre.univesp.br/o-movimentofeminista\#.WRPDXIUrLIV > . Acesso em: o9 mai. 2017.

MESTRE, Ruth M. Mestre i. Hilando fino: migraciones autónomas de mujeres para trabajar em la indústria del sexo. In. CÁSANOVAS, Andrés Pedreño; PEDREÑO, Manuel Hernández (Coord.). La condición inmigrante: exploraciones e investigaciones desde la región de Murcia. Murcia: Universidad de Murcia, 2005.

NASCIMENTO, Grasiele Augusta Ferreira; SOUSA, Ana Maria Viola de. Direito e cinema - uma visão interdisciplinar. Revista ética e filosofia política. Juíz de Fora. vol. 2. n. 14. Outubro, 2011. Disponível em: < http://www.ufff.br/eticaefilosofia/files/2011/10/14_2_ sousa_nascimento_8.pdf $>$. Acesso em: 08 mai. 2015.

NAÇÕES UNIDAS. Relatório de desenvolvimento humano 2010. A verdadeira riqueza das nações: vias para o desenvolvimento humano. Disponível em: < http://hdr. undp.org/en/media/HDR_2010_PT_Complete_reprint.pdf >. Acesso em: 30 mar. 2011.

Relatório de desenvolvimento humano 2011. Sustentabilidade e equidade: um futuro melhor para todos. Disponível em: < http://hdr.undp.org/en/media/ HDR_2011_PT_Complete.pdf >. Acesso em: 18 nov. 2011. 
A ONU e as mulheres. Disponível em: https://nacoesunidas.org/acao/ mulheres/. Acesso em: o8 mai. 2017.

Número de mulheres em parlamentos cresce apenas o,5\% em 2015. Março, 2016. Disponível em: < http://www.unmultimedia.org/radio/portuguese/2016/o3/ participacao-das-mulheres-em-parlamentos-foi-decepcionante-em-2015/\# . WRPHblUrLIV >. Acesso em: o8 mai. 2017.

Participação feminina nos parlamentos desacelerou em 2015, diz União Interparlamentar. Março, 2016. Disponível em: < https://nacoesunidas.org/participacaofeminina-nos-parlamentos-desacelerou-em-2015-diz-uniao-interparlamentar/ >. Acesso em: o8 mai. 2017.

Women's participation rate in parliaments slows, even as more gain top seats - IPU. Março, 2016. Disponível em: < http://www.un.org/apps/news/story. asp?NewsID=53373\#.WRPG11XyvIW >. Acesso em: o8 mai. 2017.

PENA, Conceição Aparecida Mousnier Teixeira de Guimarães. A desigualdade de gênero: tratamento legislativo. Revista EMERJ, v. 11. n. 43. 2008. Disponível em: < http://www.emerj.tjrj.jus.br/revistaemerj_online/edicoes/revista43/Revista43_63.pdf >. Acesso em: o8 mai. 2017.

PINTO, Céli Regina Jardim Pinto. Feminismo, história e poder. Revista Sociologia Política. Curitiba. v. 18. n. 36. Junho, 2010. Disponível em: < http://www.scielo.br/pdf/ rsocp/v18n36/o3.pdf >. Acesso em: 11 mai. 2017.

ROESLER, Jucimara. Narrativa fílmica, imaginário e educação. Revista Sessões do Imaginário. Porto Alegre. n. 13. Setembro, 2005. Disponível em: < http:// revistaseletronicas.pucrs.br/ojs/index.php/famecos/article/viewFile/858/645 >. Acesso em: o8 mai. 2017.

SEN, Amartya. Desenvolvimento como Liberdade. São Paulo: Companhia das Letras, 2000.

TELES, Maria Amélia de Almeida. Breve história do feminismo no Brasil. 1.ed. São Paulo: Brasiliense, 1993.

VIEIRA, Liszt. Cidadania e globalização. Rio de Janeiro: Record, 2000.

YOUNG, Iris Marion. Dilemmas of gender, political philosophy and policy. New Jersey: Princeton University Press, 1997. 
Intersecting voices. Dilemmas of gender, political philosophy and policy. New Jersey: Princeton University Press, 1997.

WOOLF, Virginia. Um teto todo seu. Rio de Janeiro: Círculo do Livro, 1990. 